\title{
Effective Intervention across Socioeconomic Classes for Improvement in Language Outcomes
}

\author{
Afia Kanwal $^{1}$, Wasima Shehzad ${ }^{2}$ \\ ${ }^{1}$ Postal Address: Office 1, LTC, Humanities Department, Air University, E-9, Islamabad, Pakistan \\ ${ }^{2}$ Fulbright \& British Alumna, Faculty of Social Sciences, Air University, Islamabad, Pakistan \\ Correspondence: Dr. Afia Kanwal, Postal Address: Office 1, LTC, Humanities Department, Air University, E-9, \\ Islamabad, Pakistan
}

Received: October 7, 2016

Accepted: December 5, 2016 Online Published: December 30, 2016

doi:10.11114/jets.v5i1.1913

URL: http://dx.doi.org/10.11114/jets.v5i1.1913

\begin{abstract}
Students in higher education bring with them a difference of linguistic abilities that is often due to the difference in socioeconomic status and early schooling. The lack of linguistic capacity hampers academic pace and introduces discrepancies in performance of learners. This paper examines the persistence of socioeconomic differences being translated in educational institutes and their influence on language outcomes and it investigates the role of effective intervention through an action research model by Zuber-Skerritt (1992) called CRASP. It is an experimental study based on a sample of 300 engineering students which examines initial and final evaluation of language proficiency through intervention. The tools used to gather data include demographics, language test of writing and speaking skills and sequential assessment. The results showed that intervention is helpful for enhancing language proficiency nonetheless; the improvement rate is nearly negligible and requires a long-term plan to impact early disadvantage of exposure.
\end{abstract}

Keywords: higher education, language proficiency, socioeconomic status, intervention, action research, outcomes

\section{Introduction}

The need of English proficiency skills in higher education is more in demand than ever before due to globalization and the availability of information and technology in English. Students in higher education are expected to compete internationally and transfer academic knowledge which is only possible through English language. An enhanced focus on improved outcomes is the prime goal of any university course as universities prepare students for competitive markets therefore; studies of issues and challenges that hamper this process must be addressed. In this regard, the role of universities in preparing students with a higher level of English proficiency skills is crucial.

Universities provide skills necessary for labor markets and produce future professionals. Most important of these skills is the skill of English language as noted by Hoodbhoy who says that an "Ideal University creates a modern citizenry capable of responsible and reasoned decision making. Its graduates can think independently ....and are capable of coherent expression in speech and writing" (Hoodbhoy, 2009, p. 581). The role of universities in development cannot be denied; one of the key skills that higher education in developing countries can employee is the 'linguistic key'; the English language skill. However, a constant decline in the skills of English language has been observed in universities which have started receding in producing more knowledge in English and participating lesser than before with the outer world in academic contexts. Linguistic competence is a combination of different skills that influence ones overall approach to life by refining ones capabilities, thinking, knowledge and abilities to have an understanding of the environment where one can perform their particular role. No matter what the area of study is, linguistic skills can sharpen the benefit one receives from it. Language has thus become one of the most important areas of concern to higher education which looks towards enhanced outcomes. Regardless of this realization there are individuals who are successful at attaining the language skills and there are those who lag way behind.

University education is linked to early experience of school and family socioeconomic status. Ahmad (2013) states that "for the improvement of quality in higher education, primary education needs to be improved, because it provides foundations for the building of higher education". From the above argument regarding importance of English and its role in ones chances of success and development, it is clear that a language skill is related to ones success at different stages of one's life and it is a skill on which one builds on step by step. The initial linguistics input and environment is 
clearly linked to later language proficiency and chances of one's success in higher education.

Higher education however, faces a common problem when students arriving in university bring with them a difference in their language communication ability to start with that is often due to the difference in socio-economic status and early schooling. The lack of linguistic capacity of learners in higher education hampers their academic pace and introduces discrepancies in performance. In this regard, the role of early schooling and their relationship to language proficiency skills and their role in reproducing the social inequality trends in education mainly through the use English as a tool is one of the most important issues that if tackled can benefit both schooling and higher education in bridging the gaps thus created.

On one hand this paper aimed to examine the persistence of socio-economic class differences being translated in educational institutes and their influence on language outcomes while on the other it investigated the role of effective intervention through CRASP (Critical attitude, Research into teaching, Accountability and Self-evaluation leading to Professionalism) model of action research by Zuber-Skerritt (1992) on language outcomes. The paper also aims at finding out the impact of intervention designed to address the language gaps in university language classes that are created by early differences of socio economic class and schooling on the language outcomes.

\section{Literature Review}

While better linguistic outcomes and higher achievement is the aim of higher education, these concepts cannot be explained in vacuum and have a history in their making; it is this history, culture and society exposure which needs to be unlocked within the institutional exposures that children come across early in their life which becomes deterministic while they enter into higher education. The early exposure of schools and socioeconomic status is what divides the levels of achievements one can attain in university years.

In this regards, Lareau (2011) states that social class matters in the lives of young people, it matters in their high school, in their transitions out of high school and in their options of work. Other researchers too point out similar facts. Oscar Lewis (1959) work about understanding poverty which saw family as the primary source leading to disadvantage in institutions, Basil Bernstein's (1970) study of restricted code used by the impoverished group as oppose to the middle class families, Pierre Bourdieu's (1977) study which referred to the lack of 'habit, skill and information' and 'cultural capital' in lower classes, James Colemen's (1990) report on the lack of social norms and social networking and 'social capital' of different socioeconomic classes, Prandy's (2003) work which concludes that family background has been increasingly significant for educational success, Moore's (2001) idea that 'different types of schools teach different forms of knowledge' and inculcate different skills, levels of skills and different ways of problem solving and understandings, Berns (2012) research that noted 'middle class are exposed to different language and cognitive experiences than are lower class children are all studies in the area which relate early school experience and socioeconomic statute responsible for its influence in linguistic achievement. Similar views are presented by Krashen \& Brown (2005); Van Steensal (2006); Feyerherm (2008); Bowles \& Gintis (1976); Aikens and Barbarin (2008); Akram \& Ghani (2003) and Shamim (2011).

Nevertheless, in university years it is necessary to realize that all individuals receive equal exposure regardless of their early experience hence their outcomes should fall together. Moreover, early differences can also be removed by interventions in higher education that can be carried out through teaching. Crowther (2009) stated that the teacher being a leader framework must have a broadened version to implement what they see and understand as correct in a given situation. They must act as leaders enhancing learning and view learning as a process with eyes on the product, understand students prior learning, organize material to be learned, maintain student motivation, allow time for practice to develop skills, provide feedback, understand surrounding and develop a climate for students to learn and be self-directed. Issues and challenges for practitioners in reducing gaps and bringing about equity in language learning experiences of higher education can be handled with proper understanding of teacher's role in assessing the problem and applying intervention techniques and models as was used in this research through CRASP model which is explained in the following section.

\section{Methodology}

This research is quantitative in nature and combines action research with experimentation as a method to gather and interpret data. It is based on a sample of 300 engineering students where 250 served as an experimental group to help examine initial and final evaluation of language proficiency through CRASP based model of intervention. A group of 50 students served as a control group to this sample. On one hand it aims to examine the reflection and persistence of socio-economic class and early school differences in higher education and its influence on language outcomes while on the other it investigates the role of effective intervention on socioeconomically diverse student population. The tools used to gather data included demographics, language test of writing and speaking skills and sequential assessment. A brief description of the methods used is given below. 
Where educational research deals with 'critical inquiry' that is primarily aimed at decisions to improve 'educational action', action research deals with a systematic inquiry of one's own practice with a specific focus on improvement. It not only understands and evaluates yet improves educational practice according to Bassey (1998). Coghlan and Brannick (2005) define it as both sequence of events to a process and an approach to solving problems that orients the researcher to a rather positive stance to look into the issues involved.

Action Research model of CRASP (Critical attitude, Research into teaching, Accountability and Self-evaluation leading to Professionalism) first presented by Zuber-Skerritt (1992) is a model for higher studies which identifies different steps to solve problems. The model focuses on identifying a problem, thinking of ways to tackle it, taking action, reflecting and intervening to handle the problem. The mode is appreciated for its usefulness and applicability in higher education. It is a theoretical frame based on which higher education teaching and learning is informed through a self-reflective action research method which helps develop professionalism as a continuous effort to solve problems. The model of CRASP improves ways of achieving the goals of higher education that can influence positive outcomes. It informs the research by practitioners who link theory and method by intervening with curricula and modifying pedagogy in order to have a positive influence on the learners' achievements. The intervention used for this research is based on CRASP model and is divided into a set of procedures that were finalized by a panel of language experts in a specific designated session. These are given below:

1. Identification of problem

Low achievement levels in higher education persistent due to different socio economic classes and early school exposures

2. Development of hypothesis

$\mathrm{H}_{1:}$ Performance of learners' language in terms of writing skill and speaking skill varies in universities even when all the learners are provided equal exposure regardless of their backgrounds.

$\mathrm{H}_{0 \text { : }}$ Performance of learners' language in terms of writing skill and speaking skill does not vary (grows constantly) in universities as all the learners are provided equal exposure regardless of their backgrounds.

$\mathrm{H}_{1:}$ Language outcome trends are predictable in all cases with respect to socioeconomic class and early schooling

$\mathrm{H}_{0}$ : Language development trends are not predictable in all cases with respect to socioeconomic class and early schooling

3. Application of intervention program

The intervention stages included an initial study of the sample and a step by step application process which is described as follows.

I. Initial study: Through demographics complete background information of learners, earlier grades of English subjects in matric and secondary school, social class and need analysis with respect to social class was carried out. Once the basic Information was collected from the sample, it was tracked and assessed throughout their course of English in university in order to see their progress in language.

II. Intervention: One group received treatment while the other group did not receive any treatment and were taught through regular teaching ways. The first group was taught regardless of any consideration to their socioeconomic status while the second group who received treatment was exposed to an enhanced teaching session carried out over a period of two semesters with a specific focus to improve learners' language skills through intervention in the pedagogical practice with respect to their socioeconomic class information. This practice was divided into a number of intervention steps at the level of pedagogy, curriculum, and use of university resources. These steps are as follows.

1. The sample was placed into socioeconomic groups to support learners understanding of tasks within language classroom. Each group consisted of a group leader and students from different social classes and schooling to work together. Earlier students worked in groups with similar social classes and schooling and avoided mixing.

2. Teacher learner interaction was enhanced during the class; the class was divided into different stages, introduction of the lesson, individual work, group work and discussion with the teacher. In each two hour class fifteen minutes were allotted to discussing leaners issues with the assigned tasks, to make things clear and to motivate them.

Moreover, extra hours after class were allocated to support learners by giving them out of class projects in which they interacted with each other and the instructor. Independence of ideas in making decisions regarding projects was encouraged and discussed. Out of class group work was encouraged 
3. During class practice specific attention was paid to the learners who belonged to low SES or were under confident or de-motivated. Individual students who were weaker were guided specifically and encouraged during class activities. Moreover, learners who held back in class due to lack of confidence were encouraged to participate and interact.

4. Meaningful activities which were learner centered as class discussions and role plays, situation based writing, and presentations were designed specifically to allow language practice.

5. Curriculum was modified to include reading and listening as receptive skills and the content was reorganized. Order of topic was devised from easy to difficult.

6. Learners pace was considered throughout the course. They were given time to revise, discuss and practice language content.

7. Use of university resources that included library, lab was encouraged.

8. Class assessment which usually starts from the first week of the course study was delayed to the third week to allow maximum time to introduce the course requirements and basics in the first weeks of the classes. Moreover, students were given extra practice of grammar, writing and speaking activities that were meant specifically designed to overcome the problems in language. The exercises were designed after a need analysis in which students pointed out the area of difficulty in language. Individual groups of students were given extra work to finish outside class while working with each other. Reviews of basic skills, oral and writing were taught in the first month of the semester after which students were directed to the course.

9. Ongoing assessments were discussed with each learner individually and they were encouraged and guided accordingly. Sequential assessment was notified for each activity throughout the intervention for the whole sample based on which initial and final differences were measured.

10. In the third week of the semester, exercises of writing assignment, presentations and discussions were assessed and the feedback was given to individual students and they were asked to work on specific areas. Feedback was modified to encouraging rather than pointing out problem areas.

11. Students were encouraged to self-assess and peer assess the writing exercises and speaking sessions.

12. Class quizzes were announced beforehand to reduce unnecessary pressure and provide more time to practice each new lesson.

13. In order to rule out bias of individual samples extra measures that were taken are as follows.

a. Prior marks/grades in English studied as a subject in secondary school (matric) and higher secondary school (Intermediate) were gathered. While allocating students to particular social classes based on individual demographics, the school they studied from and the marks they obtained in matric and secondary school too were considered before applying interventions. These marks ruled out the possibility that the language exposure a learner received in school has undergone large shift during the transitions stage as individuals moved from secondary school to higher secondary and eventually to university.

b. The students who attended extra courses of English apart from the regular courses taught in schools before entering university were excluded from the sample as there was a possibility of results being skewed due to this extra language exposure.

c. The allocation of students to different social classes was based on purposive sampling, however, selection of students within groups was based on random sampling with no prior distinction as to who may be included or excluded.

d. The results obtained for individual sample were assessed by more than a single instructor to rule out any bias individual teachers may have for the sample. Hence, the overall results in speaking and writing classes consisted of assessment carried out by more than a single teacher. Hence, assessment was carried out by a teacher who had complete information about the students' backgrounds and socioeconomic classes and it was also carried out by a teacher who had no information about the social classes and backgrounds of the students and orientations towards the purposes of this research. The assessment marks of both the teachers were placed side by side to ensure the credibility of assessment and to reduce bias in final results.

e. Sequential assessment was continuously updated before considering the final outcomes results for plotting data. Language achievement ability was measured through initial linguistic standing, ongoing sequential assessment and before and after intervention outcome difference. 
f. A general proficiency test for writing and speaking was designed and conducted for the experimental group. The test was designed with respect to the common European framework of reference (CEFR) for foreign language learners.

Speaking skills included simple conversation in an authentic context, presentation, picture description, and role play. Writing skills included essay/creative writing, argumentative writing, picture description and question formation.

g. Language Assessment framework was devised to allocate learners to different levels based on their language performance. Higher education commission curriculum for university students was referred to however; it was in a limited form and did not specify learners' levels in terms of outcomes hence, CEFR (Common European framework of Reference for Languages) standards for foreign language learners was selected as a frame of reference.

Based on this framework a Rubric for assessment of language skills was designed in the form of a language rating scale from $0-10,0$ being the poorest and 10 being the highest. Moreover, it was based on four levels derived from the framework of reference. The criteria of an average expected range of performance for each level of linguistic assessment is given below.

I. Above range: 90-100-Exceptional II. High range: 70-89-Advanced

III. Middle range: 50-69-Developing IV. Low range: 30-49-Beginners

V. Below range: 0-29

h. Finally, the demographic data was separated from the collected linguistic samples and the students with high, average and low performance were sorted with respect to their language performance without a look at the demographic data by another person who was unaware of the research objectives. The respective person was asked to sort out data with respect to high, middle and low class based on the performance of the written and spoken samples. The results of this exercise were cross matched with the researches results and in $80 \%$ of the cases the data was accurately sorted with respect to the socioeconomic class and linguistics performance.

i. Overall achievement difference was measured across the complete sample of university learners once without the intervention and secondly after the intervention to find out the percentage of improvement across the different socioeconomic groups in terms of language outcomes across socioeconomic class.

\section{Findings}

Intervention through CRASP model was based on the application of a rigorous process of pedagogical practices that were informed through research into teaching to challenge the linguistic competency of individuals from variety of socioeconomic backgrounds to test the hypothesis. The initial, ongoing and final outcomes of the sample were attained for all the socioeconomic groups of the sample and compared within and across the data for findings. The data was characterized in terms of final linguistic outcomes of socioeconomic groups before and after intervention to see the difference.

\subsection{Overall Linguistic Capacity Based on Test Scores}

Overall linguistic capacity of the university sample was based on scores of the test. The test was divided into two sections; namely writing and speaking skills. The writing test was based on three questions which covered essay/creative writing, descriptive writing, argumentative writing and question formation. The speaking test was based on individual speaking session in which each individual presented a view point and supported or argued against it, picture description, Presentation and role play. In role plays the participants were graded for individual performance. Each table/graph is presented and elaborated in the descriptions below.

\subsubsection{Speaking Skills Test Scores}

The table presents the speaking scores obtained through the speaking test of the university sample. The mean scores, maximum, minimum, range and mode for each social class are shown across the respective label. The mean value in low social class is lowest, in the middle class it is at average whereas in the high class it is highest. It is clear from the maximum and minimum values that the performance for each social class has a wide range which means not all students in each social class perform equally well and vary from low to expected range for each social class. In some cases they also perform better than the expected range. 
Table 1. Mean test Scores of speaking skill across SEC

\subsubsection{Writing Skills Test Scores}

\begin{tabular}{|c|c|c|c|c|c|c|}
\hline & & Mean & Maximum & Minimum & Range & Mode \\
\hline Low & Conversation (LC) & 4 & 7 & 2 & 5 & 3 \\
\hline \multirow{3}{*}{$\overline{\mathrm{SEC}}$} & Presentations (LP) & 6.5 & 6 & 1 & 5 & 5 \\
\hline & Picture description (LPD) & 4.5 & 6 & 1 & 5 & 4 \\
\hline & Role play (LRP) & 5.2 & 5 & 2 & 3 & 4 \\
\hline Middle & Conversation (MC) & 5.2 & 7 & 3 & 4 & 6 \\
\hline \multirow[t]{3}{*}{ SEC } & Presentations (MP) & 7.4 & 8 & 4 & 4 & 6 \\
\hline & Picture description (MPD) & 6.8 & 8 & 3 & 5 & 6 \\
\hline & Role play (MRP) & 6.9 & 8 & 2 & 6 & 5 \\
\hline High & Conversation (LC) & 8.3 & 10 & 5 & 5 & 8 \\
\hline \multirow[t]{3}{*}{ SEC } & Presentations (LP) & 8.4 & 10 & 5 & 5 & 7 \\
\hline & Picture description (LPD) & 9.3 & 10 & 6 & 4 & 7 \\
\hline & Role play (LRP) & 9.5 & 10 & 5 & 5 & 7 \\
\hline
\end{tabular}

Table 2. Mean test Scores of writing skill across SEC

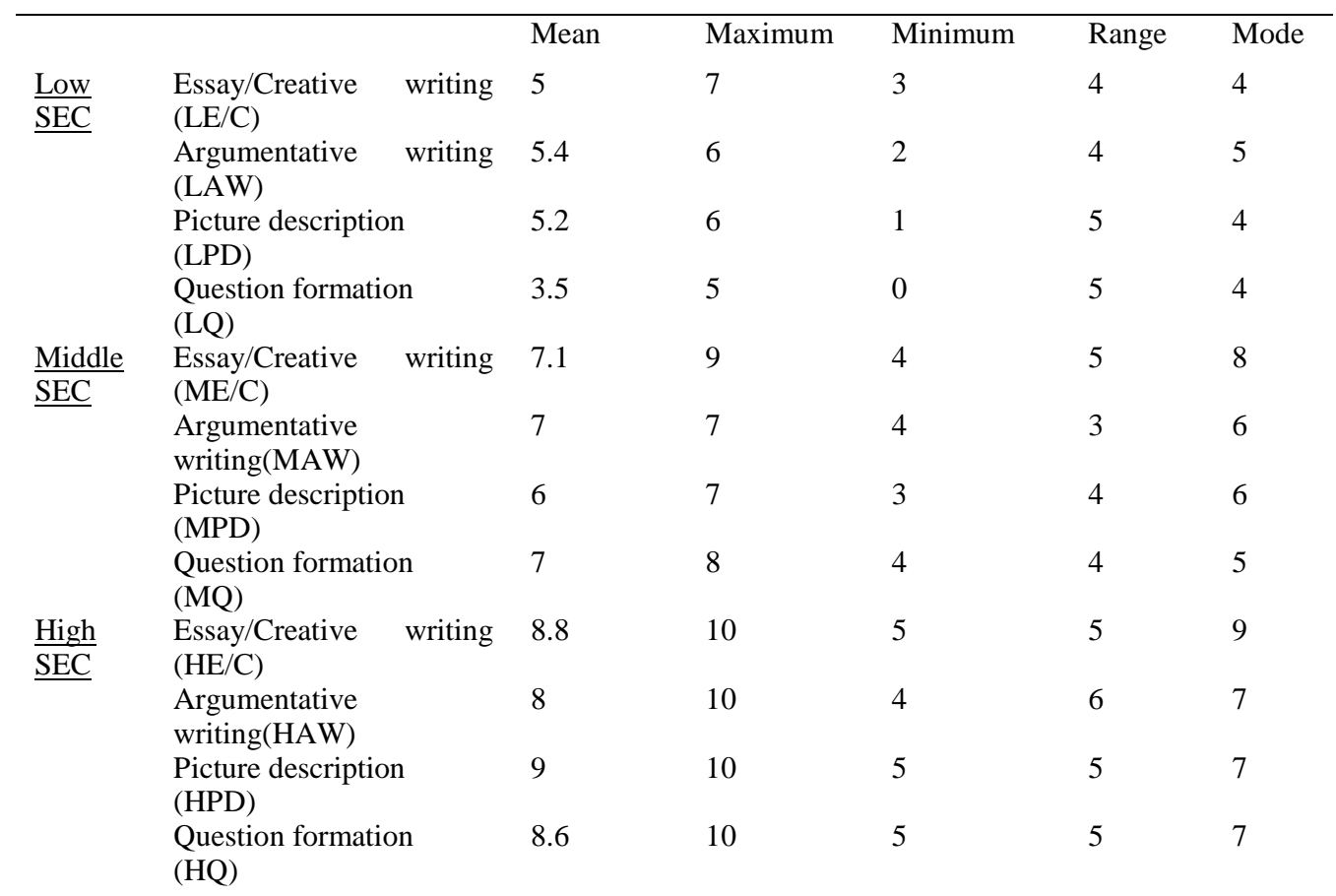

The table presents the writing scores obtained through the writing test of the university sample. The writing test was based on essay/creative writing, argumentative writing, and picture description and question formation. The mean scores, maximum, minimum, range and mode for each social class are shown across the respective label. The mean value in low social class is lowest, in the middle class it is at average whereas in the high class it is highest. It is clear from the maximum and minimum values that the performance for each social class has a wide range which means not all students in each social class perform equally well and vary from low to expected range for each social class. In some cases they also perform better than the expected range.

The writing competency of low and middle paid social class school was observed to be closer to each other in pre-test whereas the high social class sample produced written competency that was significantly higher. The trend was observed to change in university as students who had a low socioeconomic class perform better after intervention but at the same time they remain within the expected range of their performance. Similarly, the students of middle socioeconomic class showed performance that was scattered towards advanced linguistic ability as well as lowered ability.

\subsection{Comparison of Linguistics Proficiency after Interventions}

The linguistics ability of the sample is measured by mean values of initial performance before intervention and final performance after intervention of speaking and writing skills. This is considered to be the overall measure of linguistic improvement across socioeconomic class after intervention. The results obtained from this are displayed and discussed below. 


\subsubsection{Results for Speaking Performance}

Table 3. Initial and final speaking performance across SEC

\begin{tabular}{lll}
\hline & S1(Initial) & S2(Final) \\
\hline Low SEC & 6.1025 & 6.5331 \\
Low SEC & 6.692917 & 7.092083 \\
Middle SEC & 7.5766 & 7.7597 \\
Middle SEC & 7.3125 & 7.520833 \\
High SEC & 8.042917 & 8.395833 \\
High SEC & 8.0845 & 8.3857 \\
\hline
\end{tabular}

The table presents the initial and final speaking scores across low, middle and high social class in the university sample. As the data set was large hence the data was divided into two sets and the mean scores for both sets across each socioeconomic class are presented in the above table. It is clear from the data in the table that there is a slight difference in the mean values of the initial and final speaking performances across all social classes however, in low social class after intervention there is notable improvement. Moreover, the difference is minor and remains within the expected range of each class. This means that after intervention the overall change in the speaking skills remains close to the initial score however, in low social class the speaking ability is enhanced which means that intervention influenced the students from low social class.

4.2.2 Results for Writing Performance

Table 4. Initial and final writing performance across SEC

\begin{tabular}{lll}
\hline & W1(Initial) & W2(Final) \\
\hline Low SEC & 5.9441 & 6.2129 \\
Low SEC & 6.61875 & 6.91625 \\
Middle SEC & 7.487 & 7.6 \\
Middle SEC & 7.38125 & 7.495 \\
High SEC & 7.955417 & 8.024583 \\
High SEC & 8.6218 & 8.9207 \\
\hline
\end{tabular}

The table presents the initial and final writing scores across low, middle and high social class in the university sample. As the data set was large hence the data was divided into two sets and the mean scores for both sets across each social class are presented in the above table. It is clear from the data in the table that there is a slight difference in the mean values of the initial and final writing performances. However, the difference is minor and remains within the expected range of each class. This means that after intervention the overall change in the writing skills remains close to the initial score.

\subsection{Results for T-test and Analysis Of Variance (ANOVA)}

The mean values are calculated however, it is very much likely that the means of the two populations are the same and the difference has occurred only by chance. In order to rule out this possibility it was necessary to calculate probabilities with which it can be ensured that the difference observed reflects a true difference instead of one that has occurred in the course of random sampling. Hence, t-tests and ANOVA and $p$ values were calculated based on which the hypothesis are either rejected or accepted. These are given below.

\subsubsection{Initial and Final Performance Comparison T-test of Writing and Speaking}

A paired T-test was conducted to compare the two values of initial and final performance of writing and speaking. The results of the $t$ test are presented in the table below. 
Table 5. T-test comparison of initial and final linguistics performance

Writing Paired Samples Statistics Speaking

\begin{tabular}{|ll|r|r|r|r||l|l|l|}
\hline & & Mean & $\mathrm{N}$ & $\begin{array}{c}\text { Std. } \\
\text { Deviation }\end{array}$ & $\begin{array}{c}\text { Std. Error } \\
\text { Mean }\end{array}$ & Mean & $\begin{array}{l}\text { Std. } \\
\text { Deviation }\end{array}$ & $\begin{array}{l}\text { Std. Error } \\
\text { Mean }\end{array}$ \\
\hline Pair 1 & Initial Low SC. & 6.2814 & 2 & .47705 & .33733 & 6.3977 & .41749 & .29521 \\
& Final Low SC. & 6.5646 & 2 & .49734 & .35167 & 6.8126 & .39526 & .27949 \\
Pair 2 & Initial Middle SC. & 7.4341 & 2 & .07478 & .05288 & 7.4446 & .18675 & .13205 \\
& Final Middle SC. & 7.5475 & 2 & .07425 & .05250 & 7.6403 & .16890 & .11943 \\
Pair 3 & Initial High SC. & 8.2837 & 2 & .02940 & .02079 & 8.0637 & .02940 & .02079 \\
& Final High SC. & 8.4708 & 2 & .00717 & .00507 & 8.3908 & .00717 & .00507 \\
\hline
\end{tabular}

\begin{tabular}{|c|c|c|}
\hline \multicolumn{3}{|c|}{ Std. Error Mean } \\
\hline & Writing & Speaking \\
\hline \multicolumn{3}{|l|}{ Initial/Final SC. } \\
\hline Pair 1(Low) & .032 & .024 \\
\hline Pair 2(Middle) & .002 & .041 \\
\hline Pair 3 (High) & .050 & .050 \\
\hline
\end{tabular}

Null hypothesis that performance remains same before and after intervention is rejected. There is a slight improvement in overall results. However, the writing competency across class grows steadily within the expected range. The values are statistically significant means that all values have gone through change from initial to final performance; also as $\mathrm{p}$ is less than 0.05 hence null hypothesis that the values remain same after interventions is rejected.

4.3.2 Initial and Final Performance across Low, Middle and High Class ANOVA

One way analysis of variance (ANOVA) was used to study the three samples which are low, middle and high social class performances of speaking and writing. The three categories were considered to be independent variables. The null hypothesis of ANOVA was that the mean is same for all the socioeconomic groups. The alternative hypothesis was that the mean is not the same for all the groups.

Table 6. Results of ANOVA

ANOVA Results of Speaking
\begin{tabular}{|l|l|l|l|l|l|l|l|l|}
\hline $\begin{array}{l}\text { Source } \\
\text { of } \\
\text { variation }\end{array}$ & $\begin{array}{l}\text { Sum of } \\
\text { squares }\end{array}$ & D.F & $\begin{array}{l}\text { Mean } \\
\text { squares }\end{array}$ & F & $\begin{array}{l}\text { Sum of } \\
\text { squares }\end{array}$ & D.F & $\begin{array}{l}\text { Mean } \\
\text { squares }\end{array}$ & F \\
\hline Between & 5.305 & 2 & 2.652 & 33.52 & 7.686 & 2 & 3.843 & 27.97 \\
\hline Error & 0.7122 & 9 & 7.9138 & & 1.236 & 9 & 0.1374 & \\
\hline Total & 6.017 & 11 & & & 8.922 & 11 & & \\
\hline
\end{tabular}

The probability of this result, assuming the null hypothesis, is less than .0001

\begin{tabular}{|c|}
\hline $\begin{array}{l}\text { Speaking } \\
\text { Group A: Low }\end{array}$ \\
\hline $\begin{array}{l}\mathrm{N}=4,6.106 .536 .697 .09, \text { Mean }=6.6051,95 \% \\
\text { confidence interval for Mean: } 6.287 \text { thru } 6.923 \text {, } \\
\text { Standard Deviation }=0.409, \text { High }=7.092 \text { Low }= \\
6.103 \text {, Median }=6.613 \text {, Average Absolute Deviation } \\
\text { from Median }=0.287\end{array}$ \\
\hline Group B: Middle \\
\hline $\begin{array}{l}\mathrm{N}=4,7.317 .527 .587 .76 \text {, } \\
\text { Mean = 7.5424, 95\% confidence interval for Mean: } \\
7.224 \text { thru } 7.861 \text {, Standard Deviation }=0.184 \text {, High }= \\
\text { 7.760, Low }=7.313 \text {, Median }=7.549 \text {, Average } \\
\text { Absolute Deviation from Median }=0.126 \\
\text { Group C: High }\end{array}$ \\
\hline $\begin{array}{lr}N=4,8.048 .088 .398 .40, & \text { Mean } \\
=8.2272,95 \% \text { confidence interval for Mean: } & 7.909\end{array}$ \\
\hline $\begin{array}{l}\text { thru } 8.545, \quad \text { Standard } \quad \begin{array}{l}\text { Deviation }= \\
\text { High }=8.396 \text { Low }=8.043, \text { Median }=8.235,\end{array} \text { Average } \\
\text { Absolute Deviation from Median }=0.164\end{array}$ \\
\hline
\end{tabular}

\section{Writing}

Group A: Low

$\mathbf{N}=4,5.94,6.21,6.62,6.92$, Mean $=6.4230,95 \%$ confidence interval for Mean: 6.004 thru 6.842, Standard Deviation = 0.430 , High $=6.916$, Low $=5.944$, Median $=6.416$, Average Absolute Deviation from Median $=0.345$

\section{Group B: Middle}

$\mathbf{N}=\mathbf{4}, 7.38,7.49,7.50,7.60$,

Mean $=7.4908,95 \%$ confidence interval for Mean: 7.072 thru 7.910, Standard Deviation $=8.936 \mathrm{E}-02$, High $=7.600$ Low $=7.381$, Median $=7.491$, Average Absolute Deviation from Median $=5.669 \mathrm{E}-02$

Group C: High

$\mathbf{N}=4,7.96,8.02,8.62,8.92, \quad$ Mean $=8.3806$, $95 \%$ confidence interval for Mean: 7.961 thru 8.800 , Standard Deviation $=0.468$, High $=8.921 \quad$ Low $=$ 7.955, Median $=8.323$

Average Absolute Deviation from Median $=0.391$ 
The ANOVA test procedure produced an F-statistic $=33.52$ for speaking and 27.97 for writing, it was used to calculate the p-value, with the help of which the hypothesis can be measured with respect to its accuracy. The value of $p .001$ for both speaking and writing, since $p<0.05$ hence the results are extremely statistically significant. With $p$-value there is enough evidence to reject the null hypothesis and accept the alternative hypothesis. Ho is hence not true as standardized variances are not equal to each other. It is therefore concluded that there is difference and that the average of the dependent variable is not the same for all the groups. The problem with $\mathrm{p}$ value is that it does not tell which means are different. For this the Euclidean difference was measured to measure exact distance between values.

Finally, the results of CRASP mean that intervention is helpful nonetheless, the improvement rate is nearly negligible and requires a long-term intervention to overcome the impact of early disadvantage of exposure to language. It also signifies that the students who had schooling from a certain school continue to perform in line with the same rate overtime in language ability and do not make notable transitions but at the same time continue to grow at a notably small rate. The research results suggested that individuals would benefit from intervention programs developed to reduce the gap of linguistic achievements. However, there are no quantum jumps of performance in writing and speaking skills of students of one social class or the other.

Overall achievement difference was measured across the complete sample of university learners once without the CRASP model application and secondly after the intervention to find out the percentage of improvement across the different socioeconomic groups in terms of language attainment levels.

In low social class the Euclidean difference of initial and after intervention showed 0.401 difference in writing and 0.587 in speaking skills whereas in middle class .152 difference in writing and 0.263 in speaking skills respectively appeared in initial and final linguistic attainment level. Similarly, 0.3 differences in writing and 0.5 in speaking skills appeared in initial and final linguistic attainment level of high social class. The progress noted in writing and speaking skills after the intervention through the CRASP model was precisely trivial although, it existed. This signifies the strong influence and relation of early schooling and family background to the overall linguistic attainment of an individual over the course of lifetime. The results of CRASP signify that intervention is helpful nevertheless; the improvement rate is nearly negligible and requires a long-term intervention to overcome the impact of early dis-advantage of exposure to language. Hence, it is concluded that though students from each class received similar exposure of curriculum, pedagogy and exposure yet, they performed in line with the expected range set for their specific social class instead of exhibiting quantum jumps in linguistic proficiency even after the intervention program.

\section{Conclusions}

University education is designed in a way to eradicate early differences in linguistic exposure through equal exposure of curriculum and pedagogy based on which it is expected that the intervention applied should lead to equal outcomes across socioeconomic classes. The results in this research however, indicate that the students of specific class who had schooling with respect to their SEC continued to perform in line with the same rate overtime in language ability and did not make notable achievements. Moreover, Family socio-economic status and institutional exposure combined together provide understandings to how individuals evolve under the impingement of structures (Schafer et al., 2011). Implicit efforts revolve around the level of linguistic ability that is handed over to children across different socioeconomic classes through varying curriculum and pedagogical exposures. Though divergence among SEC linguistic proficiency occurs over time increasing inequality between individuals yet, community opportunity structures and intervention models provide advantage in terms of providing support, resources, motivation and intervention for educational nourishment and reduce the risks of linguistic failure. It means that a long-term intervention program if applied to overcome the impact of early dis-advantaged exposure to language will result in significant increase of linguistic ability. Intervening curricula, modifying pedagogy and understanding learners through intervention can help achieve goals of higher education however, unless major intervention takes place linguist ability continues to grow with the same rate throughout the years.

The results of this research also show to the practitioners how they can employ intervention to reduce performance gaps and bring about equity in language outcomes. Intervention programs have a potential towards reducing the risks of linguistic failure and increase potential of linguistic proficiency skills. Although, the change in linguistic ability across social class with income distributions and schooling with fee differences forms a replicative pattern over years (Jencks \& Phillips, 2011; Lee \& Orfield, 2006; Reardon, 2011 \& Galindo, 2009) but intervention can enhance the capability of linguistic growth by allowing individuals of particular classes to build on their linguistic proficiency overtime. Moreover, the research results suggested that individuals benefit from intervention programs developed to reduce the gap of linguistic achievements do reflect socioeconomic patterning. In future, the design and implementation of intervention programs can be of specific interest to curriculums that may be formed to equalize skills and achievements. The intervention programs can be implemented during early in their childhood years and during transition stages as 
children move from school to secondary and higher schools. The intervention programs can be implemented at entry levels to universities as well as during the university years. Moreover, the amount of exposure students receive of learning English as a communication skill rather than as a subject has to be increased. Intervention programs that ask for ability grouping must guard against the common fallacy of not reproducing class discriminations as this would be 'another nail in the coffin' (Fisher, Brooks, \& Lewis, 2002) hence, within the existing complex system the issues of linguistic disparity must be intervened with an eye for reducing disparity and not reintroducing it in models and interventions. Future research can look at possibilities and effectiveness of such practices.

\section{References}

Ahmad, I., Rauf, M., Rashid, A., Rehman, S., \& Salam, M. (2013). Analysis of the Problems of Primary Education System in Pakistan: Academic Research International, 4(2), 324-326.

Aikens, N. L., \& Barbarin, O. (2008). Socioeconomic differences in reading trajectories: The contribution of family, neighborhood, and school contexts. Journal of Educational Psychology, 100(2), 235. https://doi.org/10.1037/0022-0663.100.2.235

Akram, M., \& Ghani, M. (2013). The relationship of socioeconomic status with language learning motivation. International Journal of English and Education, 2(2), 406-413.

Bassey, M. (1998). Action research for improving educational practice. Teacher research and school improvement: Opening doors from the inside, 93-108.

Berns, R. (2012). Child, family, school, community: Socialization and support: CT, USA. Cengage Learning.

Bernstein, B., \& Solomon, J. (1999). 'Pedagogy, identity and the construction of a theory of symbolic control': Basil Bernstein questioned by Joseph Solomon. British journal of sociology of education, 20(2), 265-279. https://doi.org/10.1080/01425699995443

Bourdieu, P. (1984). Distinction: A social critique of the judgement of taste. Harvard University Press. USA

Bowles, S., \& Gintis, H. (1976). Schooling in capitalist America (Vol. 57). New York: Basic Books.

Coghlan, D., \& Shani, A. B. R. (2005). Roles, politics, and ethics in action research design. Systemic Practice and Action Research, 18(6), 533-546. https://doi.org/10.1007/s11213-005-9465-3

Coleman, J. S. (1990). Equality and achievement in education. Westview press.

Crowther, F. (2009). Developing teacher leaders: How teacher leadership enhances school success. Thousand Oaks, CA. Corwin Press.

Feyerherm, J. L. (2008). The Relationship between Socioeconomic Status and Reading Achievement in English Language Learners: Dual Language vs. English Only Programs. USA. ProQuest.

Fisher, R., Brooks, G., \& Lewis, M. (2002). Raising standards in literacy. London. Routledge. https://doi.org/10.4324/9780203166222

Hoodbhoy, P. (2009). Pakistan's Higher Education System-What Went Wrong and How to Fix It. The Pakistan Development Review, 48(4), 581-594.

Jencks, C., \& Phillips, M. (2011). The black-white test score gap. WA, USA. Brookings Institution Press.

Krashen, S., \& Brown, C. L. (2005). The ameliorating effects of high socioeconomic status: A secondary analysis. Bilingual Research Journal, 29(1), 185-196. https://doi.org/10.1080/15235882.2005.10162830

Lareau, A. (2011). Unequal childhoods: Class, race, and family life. CA, USA. California Press.

Lee, J. (2006). Tracking Achievement Gaps and Assessing the Impact of NCLB on the Gaps: An In-depth Look into National and State Reading and Math Outcome Trends. MA. Harvard University Press.

Lewis, O. (1959). Five Families: Mexican Case Studies in the Culture of Poverty. New York: Basic Books.

Prandy, K. (2003). The social interaction approach to the measurement and analysis of social stratification. International Journal of Sociology and Social Policy, 19, 215-249.

Reardon, S. F. (2011). The widening academic achievement gap between the rich and the poor: New evidence and possible explanations. NY, USA, Russell Sage Foundation.

Reardon, S. F., \& Galindo, C. (2009). The Hispanic-White achievement gap in math and reading in the elementary grades. American Educational Research Journal, 46(3), 853-891. https://doi.org/10.3102/0002831209333184

Schafer, M. H., Ferraro, K. F., \& Mustillo, S. A. (2011). Children of misfortune: Early adversity and cumulative inequality 
in perceived life trajectories. American Journal of Sociology, 116(4), 1053. https://doi.org/10.1086/655760

Shamim, F. (2011). English as the language for development in Pakistan: Issues, challenges and possible solutions. Dreams and realities: Developing Countries and the English Language, 291-309.

Van Steensel, R. (2006). Relations between socio-cultural factors, the home literacy environment and children's literacy development in the first years of primary education. Journal of Research in Reading, 29(4), 367-382. https://doi.org/10.1111/j.1467-9817.2006.00301.x

Zuber-Skerritt, O. (1992). Action Research in Higher Education: Examples and Reflections. Psychology Press. UK

\section{Copyrights}

Copyright for this article is retained by the author(s), with first publication rights granted to the journal.

This is an open-access article distributed under the terms and conditions of the Creative Commons Attribution license which permits unrestricted use, distribution, and reproduction in any medium, provided the original work is properly cited. 